\title{
COCONUT EMBRYO CULTURE: PRESENT STATUS AND FUTURE THRUST
}

\author{
BY \\ M.K. Nair and Anita Karun ${ }^{l}$
}

\section{INTRODUCTION}

The safe movement of plant genetic materials has a major concern for many countries in the world. Collecting and exchange of coconut germplasm is difficult and not economic because of the bulkiness of the seed. Moreover, due to short dormancy, the seeds germinate rapidly and thus cannot be stored for more time in a germplasm expedition. Phytosanitary restrictions too severely limit the germplasm introduction. Standardization of embryo culture technique provides an easy and safe alternative for the movement of coconut germplasm and is emphasized in the technical guidelines of FAO/IPGRI (Diekmann, 1997). In vitro culture protocols for coconut zygotic embryos have been established by various coconut research institutes in Cote d'Ivoire, France, India, the Philippines and Sri Lanka (Engelmann, 1998). An embryo culture protocol broadly consisted of at least five components, viz., field collection of embryos, in vitro active storage, in vitro retrieval, ex vitro establishment of plantlets and finally the field establishment. A detailed description of each of these components together with a comparison among different embryo culture protocols developed at various laboratories, applications made for coconut germplasm collection and development required in the future are provided here.

\section{FIELD COLLECTION}

Simple and portable equipment are used for collection and direct inoculation of embryos in the field. The collection and surface-sterilization procedures followed at different laboratories are more or less same. First the zygotic embryo along with a portion of endosperm is scooped out by means of cork borer from the dehusked and split opened nut. In some protocols, the endosperm plug itself is surface-sterilized and inoculated (Assy-Bah et al., 1987; Sossu et al., 1987; Rillo and Paloma, 1991) while in others the extracted embryo alone (Karun et al., 1993; Ashburner and Thompson 1994). Cultured naked embryos may be preferred over plugs on transportation (Ashburner, et al., 1994).

The surface-sterilization of embryo (or plug) in the field is done by using a portable inoculation hood as carrying a laminar flow is not feasible in a germplasm expedition. A portable collapsible glove box is used by Sossu et al (1987) and a folding type plexiglass hood by Karun et al. (1993). Inner surface of the hood is to be swabbed with absolute alcohol. The endosperm-plug is surface-sterilized with 5\% calcium chloride for 15-20 minutes. (Sossu et al., 1987) or first wash in ethanol, rinsed with sterile water and then rewashed in commercial bleach for 15-20 minutes (AssyBah, 1987; Rillo, 1998; Kennedy et al., 1998; Talavera et al., 1998). In the case of naked embryos, Karun et al., (1993) used 50\% chloride water (for 20 minutes) and later washed with sterile water for 3-4 times.

\section{IN VITRO ACTIVE CONSERVATION}

In vitro active conservation (short-term range) of coconut zygotic embryos becomes necessary when the collection sites are located in far-off places. The absence of either charcoal or sucrose is therefore expected to inhibit germination of embryos and their further growth (de Guzman et al., 1971; Karunaratne et al., 1985; Assy-Bah et al, 1987 and Rillo and Paloma, 1990). Assy-Bah et al (1987) could store the endosperm cylinders in $\mathrm{KC} 1$ solution $(16.2 \mathrm{~g} / \mathrm{l})$ for a period of 14 days.

\footnotetext{
${ }^{1}$ Former Director, Central Plantation Crops Research Institute (CPCRI) and Scientist (Sr. Scale) CPCRI, Kasaragod, India, respectively.
} 
Karunaratne (1988) could store the embryos in slow growth phase for 5 months in an agar based medium containing of nutrients barely sufficient for their survival. After 2, 3 and 5 months of storage, the germination on transfer to retrieval medium was reported to be 53, 40 and $32 \%$ respectively. In the case of dwarf coconut, Assy-Bah and Engelmann (1993) stored embryos for 6 months in a medium containing $2 \mathrm{~g} / \mathrm{l}$ activated carbon without sucrose and obtained $77 \%$ germination.

Karun and Sajini (1994a) observed that zygotic embryos could be stored in sterile water for 2 months ( $80 \%$ of the stored embryos germinated in retrieval medium). Compared to nutrient media, the chances of contamination of cultures are less in sterile water. Germination dropped to $13 \%$ when stored for 6 months. Embryos can also be stored for 2 months in sterile coconut water (Karun et al.., 1997). Prolonged storage of cultures at $10^{\circ} \mathrm{C}$ and $4^{\circ} \mathrm{C}$ for 3 months caused irreversible damage to the coconut embryos and no plants were recovered when transferred to the germination medium (Karunaratne, 1988).

\section{IN VITRO RETRIEVAL}

The commonly used basal media for in vitro retrieval of coconut zygotic embryos include Y3 (Eeuwens 1976) and MS (Murashige and Skoog, 1962) of which the former was specially formulated for coconut tissue. The Y3 basal medium (solid) complemented with $60 \mathrm{~g} / 1$ sucrose and $1 \mathrm{~g} / \mathrm{l}$ charcoal is used as the retrieval medium at CPCRI, India. Many other countries too use Y3 as the basal medium (liquid) for coconut embryo culture. The MS medium is used at ORSTOM/CIRAD supplemented with Morel and Wetmore (1951) vitamins, sodium ascorbate (100 mg/l) sucrose (60 $\mathrm{g} / \mathrm{l})$ and neutralized activated carbon (2 g/l) is used (Verdeil et al., 1998). A number of reports have appeared on the use of liquid nutrient medium for in vitro retrieval of coconut embryos (Sossu et al., 1987; Karunaratne, 1988; Ashburner and Thompson, 1994; Rillo and Paloma, 1992).

The culture conditions followed at different laboratories are more or less same. At CPCRI, India, the cultures are initially incubated in a dark room at $27 \pm 1^{\circ} \mathrm{C}, 85 \% \mathrm{RH}$ till the plumules emerge. Coconut embryo having no dormant period, the swelling and elongation of embryos are observed from fifth day of culture initiation. The emergence of plumule depends on the varieties; the tall took about 35-45 days and dwarf 15-25 days for germination. After germination the cultures were transferred to illuminated room approximately 2,500-3,000 lux at 16 hours photoperiod. In some laboratories the light intensity is provided up to 5000 lux at 9 hours photoperiod (Alfiler, 1998). The cultures are subcultured once in every 4-6 weeks.

The rooting of the germinated plantlet was observed to be a major problem in in vitro retrieval. In a number of experiments the in vitro retrieved seedlings were reported to have high mortality on transplantation to soil due to poor root development. At CPCRI the observations revealed that Y3 (liquid) medium supplemented with IBA $5 \mathrm{ppm}$ and NAA $1 \mathrm{ppm}$ can induce rhizogenesis. The use of rooting hormones is also reported by Rillo, 1998 and Alfiler (1998). Other procedures for increased root induction include transfer of cultures from liquid to solid medium (Balaga and de Guzman, 1971), increasing the sucrose levels (de Guzman et al., 1971; del Rosario and de Guzman, 1976), supplementing the medium with NAA (Ashburner et al, 1993) and also inorganic constituents of culture medium have been used by Balaga and de Guzman (1971); del Rosario and de Guzman (1976) and Miniano and de Guzman (1978).

The number of embryos germinated is not uniform in different laboratories. Variation is also noticed between experiments and cultivars used. The embryos of local tall cultivar WCT gives about $70 \%$ plants that can be transferred into pots for ex vitro establishment. The survival rate in vitro ranged between 40 to $86 \%$ (Engelmann, 1998). The plants will be ready for ex vitro establishment within 12 to 18 months after the first inoculation. 


\section{EX VITRO STUDIES}

The major bottleneck in coconut embryo culture in many laboratories is the poor establishment of plants in ex vitro. A positive correlation was observed between root intensity and survival in pots (Karun et al., 1993; Karun and Sajini 1994b). At CPCRI, the potting mixture consisting of sterile soil, sand and coir dust in equal proportions is used. As a precautionary measure before transplanting to the pots, the seedlings were treated with Bavistin $(1 \mathrm{~g} / \mathrm{l})$ and thereafter with IBA solution $(1,000 \mathrm{ppm})$ for one hour each. The leaves were trimmed before transplanting to reduce transpiration. Higher humidity condition was maintained initially by covering plantlets with polythene bags. Humidity was reduced gradually by providing perforations to the polythene bag and later lifting the bag during nighttime and thereafter completely. Macronutrients of Eeuwens Y3 medium were given to the plantlets once in a month for a period of 3 months. The establishment of the plantlets in the pots, polybags and field was found to be very satisfactory and comparable with seed-born seedlings. Almost all the plants transferred into pots were survived and field planted. The potting mixtures used elsewhere include sterile river sand alone or mixed with coir dust, soil and sand mixture, etc. Control of humidity received attention in all the laboratories; in some cases foliar spray of nutrients is also advocated.

\section{APPLICATIONS}

There are three well recognized applications to coconut zygotic embryo culture (del Rosario, 1998). The earlier application of the coconut embryo rescue of Makapuno, an aberrant or mutant form of coconut with soft and glutinous endosperm (de Guzman 1970; del Rosario and de Guzman, 1976, 1981). The Makapuno embryo culture is commercially applied at Philippines for mass propagation. Two other cultivars similar to the Makapuno are the Dikiri from Sri Lanka and Cocogra from Seychelles. The culture of Dikiri embryos is successfully carried out and field planted in Sri Lanka (Vidhana Arachchi et al., 1998).

An important application of embryo culture is in the germplasm collection and exchange. The protocol for embryo culture developed at CPCRI, India was successfully used in two germplasm expeditions. The first was the collection and transportation of embryos of 6 Pacific Ocean accessions maintained at the World Coconut Germplasm Center (CPCRI) Andaman Islands, India. A total of 86 embryos were field collected in $5 \mathrm{ml}$ vials containing $1.5 \mathrm{ml}$ sterile water and transported to main land. After short period of storage (15 days), the embryos were retrieved in vitro and 23 plantlets were field planted at IGB-SA (International Gene bank for South Asia) at Kidu (CPCRI, 1995, Karun et al., 1998). The contamination during the transport was $3 \%$.

The same protocol was followed by the subsequent collection of 15 exotic coconut germplasm from Mauritius, Madagascar and Seychelles (Kumaran et al., 1998). This was the first attempt in the world to collect coconut germplasm in the form of sterile embryos directly from the field. The embryos were stored in sterile water for more than one month during the expedition. The collections also include Cocogra (Makapuno type) from Seychelles and Guelle rose from Mauritius. The germination percentage after 3 months of inoculation ranges between 53.3\% (Dupaya Tall) to $89.7 \%$ (Sambava Tall). Out of the 15 embryos of Cocogra, only 2 plants survived to field planting stage. Though the germination of embryos were satisfactory, further growth and development were not uniform among the genotypes. The accessions viz. Pemba Orange Dwarf and Pemba Yellow Dwarf exhibited necrosis during in vitro culturing as well as ex vitro establishment.

The third application of embryo culture could be for in vitro screening for biotic and abiotic stress. Rillo and Paloma (1989) reported the use of in vitro plants for screening of coconut populations for resistance to cadang-cadang disease. 


\section{FUTURE THRUST}

In most of the embryo culture experiments the attention is given only for the matured embryos (about 11 months old). Such a restriction however may limit the number of available nuts during germplasm expeditions. Karun et al., (1993) investigated the feasibility of collecting embryos of 8 to 10 months old. Germination percentage of 8-month old embryos was lower than the matured ones. Better response could be obtained when sucrose was replaced with glucose in the medium. Preliminary results indicated that the dwarf embryos require more sucrose for better germination.

Genotypic difference is noticed in in vitro culture of embryos and this aspect need to be taken care while deciding on the number of culture per accessions to be collected in a germplasm expedition. Currently around 4-5 labs of different institutes have their own protocols for field collection and retrieval of embryos in vitro. Experiments to compare four protocols viz, CPCRI, India, UPLB, Philippines, PCA, Philippines and IRHO, France are initiated in these laboratories. The main objective of this coordinated experiment is to upgrade the existing embryo culture protocols for in vitro culture of mature and immature embryos with high survival rate and to apply to large number of genotypes. The role of CPCRI India is to conduct the experiments on the following objectives.

1. to compare the efficacy of four embryo culture protocols, viz., PCA, Philippines; UPLB, Philippines, IRHO, France and CPCRI, India and to study the effect of genotypes on in vitro embryo culture.

2. To study the effect of growth hormones/ osmotica on embryo maturation and subsequent germination and survival. The identified growth hormones are $\mathrm{GA}_{3}, \mathrm{ABA}$ and osmotica are PEG, mannitol, proline alone and their combinations.

The preliminary results (after 60 days of inoculation) showed no interaction between protocol and cultivars. The experiments on effect of $\mathrm{GA}_{3}, \mathrm{ABA}$ and osmotica on maturation of immature embryos are in progress at CPCRI, Biotechnology section.

Coconut genetic resources are traditionally conserved ex situ in the gene banks. The use of in vitro culture techniques including slow growth and cryopreservation represents an important additional option for the safe medium and long-term conservation of coconut germplasm. These techniques were studied in detail by Engelmann (1997). They could successfully cryopreserve and retrieve plantlets from nuts of 7-8 months after pollination. Performance of immature embryos is good due to their small size (2-3 mm length, 10-20 mg in weight) and low degree of differentiation. Immature embryos can withstand rapid freezing in liquid nitrogen after 4 hours of pretreatment on a semi-solid medium containing $600 \mathrm{~g} / \mathrm{l}$ sucrose and $10-15 \%$ glycerol or sorbitol. Large size and advanced differentiation of mature embryos render their potential use in cryopreservation problematic. The technique developed for immature embryos was successfully applied to mature embryos of four varieties (Hybrid PB 121, Cameroon Red Dwarf, Indian Tall, Renell tall (Engelmann, 1997). After 4 hours of desiccation period in the air current of laminar flow cabinet, embryos were pretreated for 11-20 hours on a medium containing $600 \mathrm{~g} / \mathrm{l}$ sucrose and $15 \%$ glycerol, then rapidly immersed in liquid nitrogen. Whole plants could be produced from $73-93 \%$ of cryopreserved embryos, depending on the variety, with only a slight delay in their regrowth rate in comparison with the control embryos.

Bajaj (1984) studied the survival of frozen WCT zygotic embryos of 1-1.5 cm size. Following storage for one month, the embryos were partially dehydrated and then cut into two transverse halves. After pretreatment with cryoprotectants (7\% DMSO + 7\% sugar in MS liquid), the embryos were blotted dry, wrapped in sterile aluminum foils, and frozen by gradually lowering into liquid nitrogen for 5 minutes. They were thawed in warm water $\left(35^{\circ} \mathrm{C}\right.$ to $\left.40^{\circ} \mathrm{C}\right)<$ washed and cultured on $\mathrm{MS}+2$, 4-D $(0.2 \mathrm{mg} / \mathrm{l})+\mathrm{NAA}(0.5 \mathrm{MG} / \mathrm{L})+\mathrm{KINETIN}(0.1 \mathrm{MG} / \mathrm{L})$. The retrieved coconut embryos and their segments showed a lag period of 4 months without any sign of growth. This 
indicated the possibility of long-term conservation of coconut germplasm. Many experiments are in progress in India and elsewhere for long-term storage of coconut zygotic embryos.

Karunaratne et al (1991) studied the feasibility of developing an in vitro technique for screening drought tolerant coconut germplasm. Water stress in the culture system was progressively increased with each passage, by incorporating polyethylene glycol (PEG-6000), mannitol and sodium chloride into culture medium. PEG and mannitol were found to have growth inhibitory action even at low concentrations. $21 \%$ of embryos of Sri Lankan Tall variety died before reaching water stress level of $170 \mathrm{mM} \mathrm{NaCl}$. About $78 \%$ survived at $70 \mathrm{mM} \mathrm{NaCl}$ concentration and only $12.6 \%$ were able to resist a concentration of $320 \mathrm{mM} \mathrm{NaCl}$. When zygotic embryos derived from two known drought susceptible cultivars of coconut, CRIC-65 and Dwarf (from Pumila) were tested using the technique, $29 \%$ and $73 \%$ of embryos respectively died due to stress damage at $170 \mathrm{mM} \mathrm{NaCl}$ concentration and none of either cultivar survived $230 \mathrm{mM}$ salt concentration. However, embryos which originated from two putative drought tolerant cultivars showed a higher survival rate when subjected to salt stress. At $170 \mathrm{mM} \mathrm{NaCl}$ concentration all the embryos developed into seedlings. In fact, germination percent of embryos was higher at $170 \mathrm{mM} \mathrm{NaCl}$ concentration than the control devoid of $\mathrm{NaCl}$. Survival percentage gradually dropped with increase in salt concentration and about $18 \%$ survived the $330 \mathrm{mM} \mathrm{NaCl}$ level.

Application of molecular techniques for screening for biotic and abiotic stress is gaining more attention all over the world. 


\section{REFERENCES}

ALFILER, A.R. 1998 Embryo culture activities at the Philippine Coconut Authority Zamboanga Research Center (PCA-ZRC) In: Coconut Embryo In Vitro Culture. (Eds. PA Batugal \& Engelmann, F) IPGRI, APO, Serdang 56-63

ASHBURNER, G.R.; THOMPSON, W, K. \& BRUCH, J.M. 1993. Effect of naphthalene acetic acid and sucrose levels on the development of cultured embryos coconut. Plant Cell Tissue, and Organ Culture, 35:157-163

ASHBURNER, G.R.; THOMPSON, W, K 1994, Coconut embryo culture for the international transfer of germplasm. In: Advances in coconut research and development (Eds. Nair, M K; Khan, H H; Gopalasundarum P; RAO, EVVB) Oxford and IBH Publishers, New Delhi, 4349

ASHBURNER, G.R.;FAURE, M G; FRANS, P R THOMLINSON, D R; PULO, P; BUNCH, J M \& THOMSON, W K 1994 Coconut embryo culture for remote locations. pp. 25-28. In: Coconut Improvement for the South-Pacific (Eds. Foale, MA and Lunch, P W) ACIAR Proceedings, No. 53

ASSY-BAH, B; DURAND-GASSELIN J \& PANNETIER C 1987. Use of zygotic embryo culture to collect germplasm of coconut (cocos nucifera L) FAO/IBPGRI Plant Genetic Resources Newsletter 71. 4-10

ASSY-BAH, B \& ENGELMANN F 1993. Medium-term conservation of mature embryos of coconut. Plant Cell, Tissue and Organ Culture, 33 19-24

BAJAJ, Y P S 1984, Induction of growth in frozen embryos of coconut and ovules of citrus. Current Science. 53. 1215-1216

BALAGA, H Y \& DE GUZMAN, E V 1971. The growth and development of coconut Makapuno embryos in vitro. II Increased root incidence and growth in response to media composition and to sequential culture from liquid to solid medium. The Philippines Agriculturist, 55. 551565.

CPCRI 1995, Annual report 1994-95 CPCRI, Kasaragod, India

De GUZMAN, E V 1970. The growth and development of coconut Makapuno embryo in vitro. The induction of rooting, Phil. Agric. 53 (2) 65-78

DE GUZMAN, E V; DEL ROSARIO, A G \& EUSEBIO, E C .1971. The growth and development of coconut Makapuno embryo in vitro III. Resumption of root growth in high sugar media; The Phil. Agric. 53, 566-579.

DEL ROSARIO, A G 1998. Status of research on coconut embryo culture and acclimatization techniques in UPLB. In: Coconut Embryo In Vitro Culture. (Eds. P A Batugal and Engelmann, F) IPGRI, APO Serdang, 12-16.

DEL ROSARIO, A G; DE GUZMAN, E V; 1976. The growth of coconut Makapuno embryos in vitro as affected by mineral composition and sugar level of medium during the liquid and solid cultures. Phil. Journal Science. 105. 215-222. 
DEL ROSARIO, A G; DE GUZMAN, E V; 1981. The status of tissue culture in Philippines. In: Proceedings of COSTED Symposium, Tissue Culture of Economically Important Plants (Ed. Rao, E N) COSTED/ANBS, Singapore, 292-294

DIEKMANN, M 1997. The use of biotechnology for the safe movement of coconut germplasms. Paper presented at International Symposium on Coconut Biotechnology Merida, December $1-51997.30$

EEUWENS, C J 1976. Mineral requirements for growth and callus initiation of tissue explants excised from mature tissues in vitro. Physiolgia Plantarum 36. 23-28.

ENGELMANN, F 1997. Cryopreservation of coconut germplasms. Paper presented at International Symposium on Coconut Biotechnology held at Merida, Yuc. Mexico 1-5 December 199734.

ENGELMANN, F. 1998. Current state of the art and problems with in vitro culture of coconut embryos. In: Coconut embryo in vitro culture. (Eds. P A Batugal and F Engelmann) IPGRI, APO, Serdang 6-11

KARUN A; SHIVASHANKAR, S; SAJINI, KK \& SAJI K V 1993. Field collection and in vitro germination of coconut embryos. J Plantation Crops 21 (Suppl) 291-294.

KARUN, A \& SAJINI K K 1994a Short term storage of coconut embryos in sterile water. Current Science 67: 118-120

KARUN, A \& SAJINI K K 1994b Coconut embryo culture: In vitro germination and ex vitro establishment. Paper presented at National Development in Plant Molecular Biology and Genetic Engineering, 29-31 Dec 1993 TNAU, Coimbatore, 23

KARUN, A \& SAJINI, K K \& IYER R D 1997. In vitro active conservation of coconut zygotic embryos. Journal of Plantation Crops 24 (Suppl) 586-593

KARUN, A; UPDHYAY, A \& PARTHASSARATHY, VA 1998. Status of research on coconut embryo culture and acclimatization techniques in India. In: Coconut Embryo in Vitro Culture. (Eds. P A Batugal and F. Engelmann) IPGRI, APO, Serdang, 29-36.

KARUNARATNE, S 1988. Short term in vitro preservation of coconut seed material: A method to facilitate field collection and transport of coconut germplasm CORD 4, 40-47

KARUNARATNE, S, KURUKULARACHCHI, C \& GAMAGE, C 1985. The culture of embryos of dwarf coconut. Cocos nucifera L. Var. Nana in vitro Cocos 3 1-8

KARUNARATNE, S; SUNIL, S \& KOVOOR A 1991. An in vitro assay for drought-tolerant coconut germplasm. Euphytica. 53. 25-30

KENNEDY, M; TEMBO, S \& MAREALLE, R 1998. Status of research on coconut embryo culture and acclimatization techniques in Tanzania. In: Coconut Embryo in Vitro Culture. (Eds. P A Batugal and F Engelmann) IPGRI, APO, Serdang, pp. 89-100.

KUMARAN, P M; KOSHY, P K; \& KARUN, A. 1998 Germplasm exchange through embryo cultures. Proceedings of $7^{\text {th }}$ Swadeshi Science Congress, 6-8 November 1997 held at CPCRI, Kasaragod, India 35-39

MOREL, G \& WETMORE, R M 1951. Tissue culture of monocotyledons. Amer. J. Bot 38: 138-140 
MURASHIGE, T \& SKOOG, F 1962. A revised medium for rapid growth and bioassays with tobacco tissue cultures. Physiol. Plant 15: 473-497

RILLO, E P 1998. PCA's embryo culture technique in the mass production of Makapuno coconuts. In: Coconut Embryo in Vitro Culture. (Eds. P A Batugal and Engelmann, F) IPGRI, APO, Serdang, pp 69-78.

RILLO, E P \& PALOMA, M B F 1989. Screening of coconut plantations for resistance to cadangcadang using in vitro plants. Philippine Coconut Authority Annual Report 155-61.

RILLO, E P \& PALOMA, M B F 1990. Comparison of three media formulations for in vitro culture of coconut embryos. Oleagineux 45(7) 319-323

RILLO, E P \& PALOMA, M B F 1991 Storage and transport of zygotic embryos of Cocos nucifera L. for in vitro culture. Plant Genetics Resources Newsletter. 86 1-4

RILLO, E P \& PALOMA, M B F 1992 In vitro culture of Makapuno coconut embryos. Coconuts Today. 9: 90-101

SOSSOU, J; KARUNARATNE, S \& KOVOOR, A 1987. Collecting palm: In vitro explanting in the field. Plant Gen Res. News March 1987 7-18

TALAVERA, C; OROPEZA, C; CAHUE, A; COELlO, J \& SANTAMARIA, J 1998. Status of research on coconut zygotic embryo culture and acclimatization techniques in Mexico. In: Coconut Embryo in Vitro Culture. (Eds. P A Batugal and F. Engelmann) IPGRI, APO, Serdang, 43-54

VERDEIL, J L; HOCHER, V; TRIQUES, K; LYAKURWA, R; RIVAL, A; DURAND-GASSELIN, T; ENGELMANN, F; SANGARE, A \& HAMON, S 1998. Status of research on coconut embryo culture and acclimatization techniques in the IDEFOR (Cote d'Ivoire) and ORSTOM/CIRAD Laboratories (France) In: Coconut Embryo In Vitro Culture (Eds. P A Batugal and F Engelmann) IPGRI, APO, Serdang, 17-28

VIDHANAARACHCHI V R; WEERAKOON, L K; FERNANDO, S C; GAMAGE, C K A \& SANTHA, E S 1998. Status of research on coconut embryo culture and acclimatization techniques in Sri Lanka. In: Coconut Embryo in Vitro Culture. (Eds. P A Batugal and F Engelmann) IPGRI, APO, Serdang, 85-88 